\title{
UC plays a crucial facilitating role in the Sierra Nevada Adaptive Management Project
}

by Adriana Sulak, Lynn Huntsinger and Susan D. Kocher

The 2004 Sierra Nevada Forest Plan Amendment adopted by the U.S. Forest Service called for using adaptive management - management through deliberate experimentation - to carry out treatments to improve forest health and reduce fire severity. The Sierra Nevada Adaptive Management Project (SNAMP), begun in 2005 and ending this year, has developed, implemented and evaluated participatory adaptive management processes in two national forests for applying fuels management treatments based on strategically placed patterns of tree thinning. SNAMP participants include federal and state agencies, the University of California and many members of the public. UC Cooperative Extension staff members have played an important role in facilitating the participation of public stakeholders. In 2010, a survey showed that stakeholders valued the learning opportunities of the project, especially appreciating the open discussions, public input and face-to-face contact with scientists. Despite the institutional limits to sharing decision making, an environment conducive to the social learning characteristic of collaborative adaptive management projects was created. The SNAMP process may lead to long-term relationships and knowledgeable stakeholders who can support the Forest Service's use of the project findings after UC's role ends.

$\mathrm{D}$ ebate over how best to prevent wildfires has continued for decades while the costs of wildfire protection and recovery have increased rapidly, with California spending \$599 million in 2013 for firefighting alone up by more than $\$ 100$ million from 2012 (NBC 2014). Federal agencies spent a similar amount in the state in 2013, with California accounting for about half of all federal spending on fire suppression.

The U.S. Forest Service manages over 20 million acres in California, much of it adjacent to homes and communities. Fire hazard management on these public lands, especially if it involves removing trees, is often argued to be essentially at a standstill (Broussard and Whitaker 2009). Large trees are especially appreciated by the public for their beauty and as wildlife habitat associated with old-growth forests, home to, for example, the endangered California spotted owl and rare

Online: http://californiaagriculture.ucanr.edu/ landingpage.cfm?article=ca.v069n01p43\&fulltext=yes doi: 10.3733/ca.v069n01p43
Pacific fisher. Controversy stemming from uncertainty about the environmental consequences of fuels treatments such as mechanical tree thinning is increasing the already substantial costs of those treatments and limiting their implementation. The gridlock led the U.S. Forest Service to specify the use of an adaptive management approach in its 2004 Sierra Nevada Forest Plan Amendment (USFS 2004).

The 2004 amendment intensified the debate about fire hazard management and environmental priorities by mandating a management strategy "with the primary objective of protecting communities and modifying landscape-scale fire behavior to reduce the size and severity of wildfires," and allowing the removal of trees larger than specified by the 2001 Sierra Nevada Forest Plan Amendment (USFS 2004). Widespread concerns arose among the public and natural resource agencies about how a program that makes fire hazard reduction a top priority might impact the forest ecosystem. In response, in 2005, the Forest Service, the U.S. Fish and Wildlife Service and the California Resources Agency signed a memorandum of understanding calling on the University of California (UC)

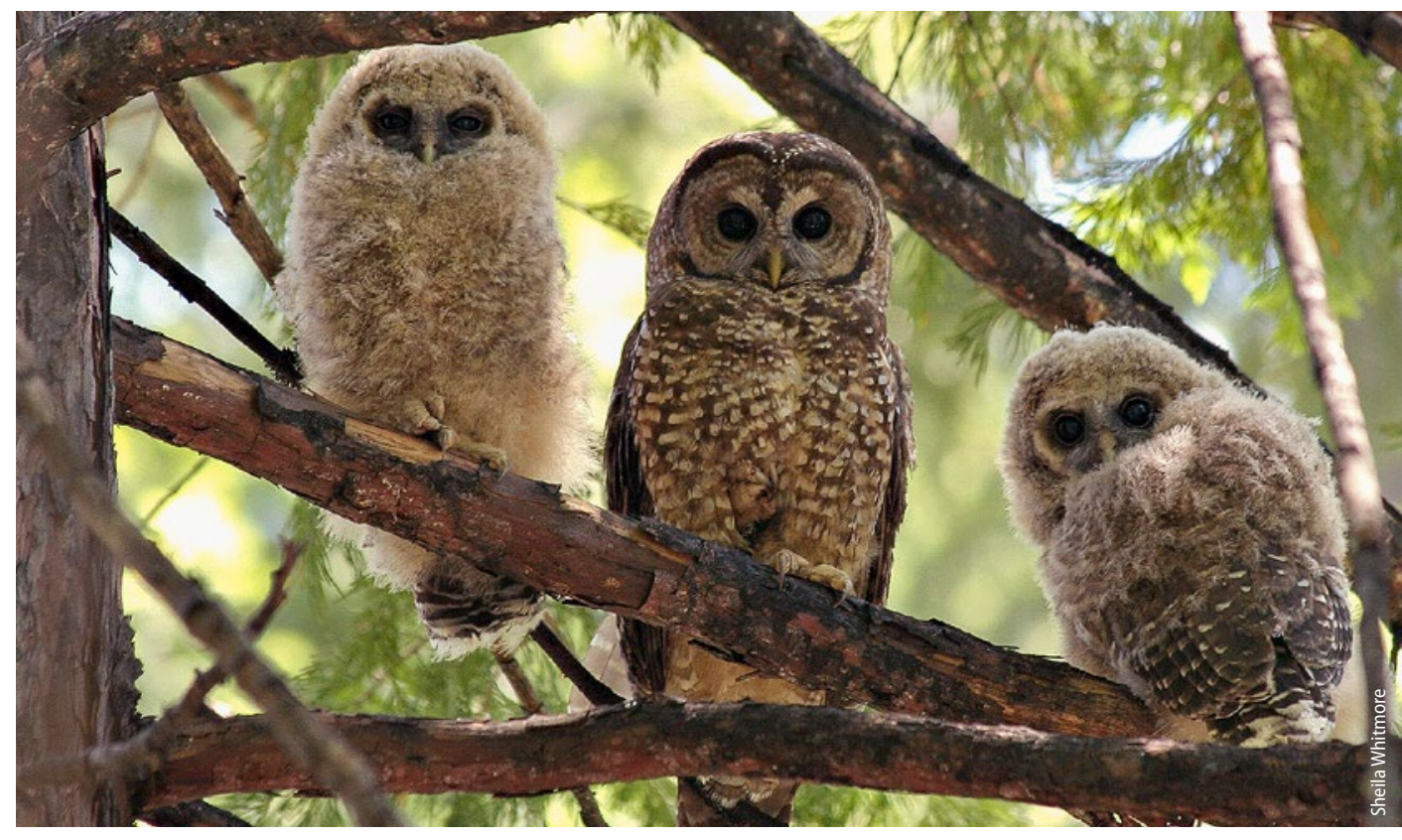

SNAMP researchers analyzed the effects of vegetation management treatments in the Sierra Nevada on forest health, fire behavior, water and wildlife such as the endangered California spotted owl. 
to act as a "neutral third party" to assist in developing a participatory adaptive management process for carrying out the forest management practices called for in the amendment. The result was the Sierra Nevada Adaptive Management Project (SNAMP 2005).

UC provided third-party science and outreach services within SNAMP; UC Cooperative Extension (UCCE) expertise in facilitating stakeholder participation was a crucial part of the project. UC was chosen for the research and outreach role because of its perceived credibility with stakeholders on both sides of the Sierra forest management debate. Other factors were UCCE's extensive network of outreach professionals and its long history of working with stakeholders on collaborative projects. UC researchers included scientists from UC Berkeley, UC Merced and UCCE; they worked with researchers from the University of Wisconsin and the

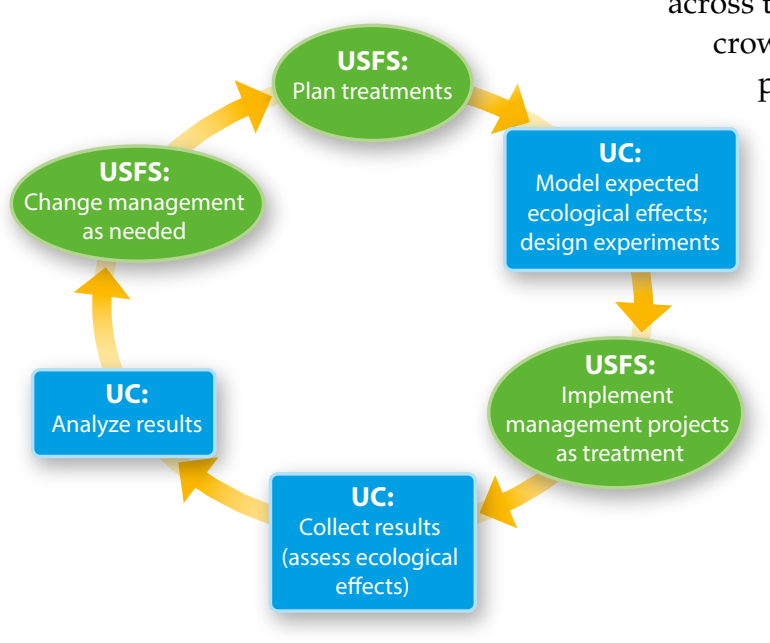

TABLE 1. SNAMP teams and their research objectives

\begin{tabular}{ll}
\hline \hline Team & Research objectives \\
\hline Public participation & $\begin{array}{l}\text { Model, research and transfer outreach and public participation strategies, } \\
\text { including use of an interactive website, strategic facilitation, collaborative adaptive } \\
\text { management workshops and integration meetings. }\end{array}$ \\
Water & $\begin{array}{l}\text { Treatment effects on streams and the forest water cycle. } \\
\text { Fire and forest }\end{array}$ \\
ecological health & $\begin{array}{l}\text { Treatment effects on fire behavior and tree morbidity and mortality. Model } \\
\text { vegetation change after treatment, along with fire behavior modeling, to simulate } \\
\text { long-term effects on wildfire spread and severity. Develop fire histories. }\end{array}$ \\
Spatial data & $\begin{array}{l}\text { Map the forest before and after treatments and measure forest habitat characteristics } \\
\text { across treated and untreated sites, including the use of Lidar technology. }\end{array}$ \\
$\begin{array}{l}\text { California spotted } \\
\text { owl (Strix occidentalis } \\
\text { occidentalis) }\end{array}$ & $\begin{array}{l}\text { Treatment effects on owl survival, occupancy and reproduction via a retrospective } \\
\text { analysis that compares } 20 \text { years of annual vegetation changes with owl demographic } \\
\text { rates in the northern study area. }\end{array}$ \\
$\begin{array}{l}\text { Pacific fisher (Martes } \\
\text { pennanti) }\end{array}$ & $\begin{array}{l}\text { Treatment effects on fisher habitat quality. Correlation of environmental factors } \\
\text { with population stability or change. Survival and behavior within four watersheds, } \\
\text { including the SNAMP southern study area. }\end{array}$ \\
\hline
\end{tabular}

beneath the trees in strategic areas. This reduces flammable material in the project area and therefore reduces the impact of a wildfire, should one occur there or nearby.

The science team designed and conducted research on treatment effects. The science team was comprised of smaller teams focused on the effects of treatments on California spotted owls, Pacific fishers, water, fire behavior and forest health, and teams focused on spatial analysis of the forest projects and on public participation (table 1). Each research team developed methods for evaluating the effects of the treatments for their area of research, informing the public about their choices and incorporating feedback when possible.

The science team reported the results of treatments back to the Forest Service and the public in order to improve future treatments in the next adaptive management cycle, and to help participants understand the effects of tree thinning on multiple resources (fig. 1). The science team's work plan stated that "adaptive management must be a participatory process that engages scientists, stakeholders, and managers in a long-term relationship grounded in shared learning about the ecosystem and society" (UCST 2007). Members of the science team signed a neutrality statement agreeing not to use SNAMP data for advocacy through the project's duration.

In conjunction with its Forest Service partners, the science team chose two study sites on the western slope of the Sierra: one in the southern Sierra, the Sugar Pine project, and the other in the northern Sierra, the Last Chance project (fig. 2). Each study site has control and treatment areas where pre- and post-treatment data were collected. Thinning treatments began in 2011 and were followed by treatments for clearing beneath the trees that included mastication (grinding, shredding or chipping) and underburning to manage fuel loads and vegetation. At this point, data collection is complete and the final report is being assembled.

The original work plan put together by UC and UCCE was peer reviewed by outside scientists, and the reviews were shared with the public. The research and outreach teams reported directly to the public, the memorandum of understanding signatory agencies and the Forest 
Service about the design, methods and outcomes of their research into the effects of chosen management treatments. Research results are being published in peer-reviewed journals — briefs of each publication and a list of publications are available at the project website, snamp. cnr.berkeley.edu. Forest Service staff, from regional representatives and district managers to field technicians, attend, and frequently present, at SNAMP events.

To include the public, as stated in the science team's work plan, from research design to interpretation of results, an outreach strategy emphasizing inclusiveness and transparency was developed using UCCE's training and experience. UCCE has coordinated and facilitated all public, researcher and manager involvement in SNAMP, including integration meetings on specific research topics, field trips, lectures, annual meetings and presentations to local, state and regional groups and local high schools, and it manages an interactive website for sharing meeting information, notes, reports and responses to comments and questions (fig. 3). UCCE
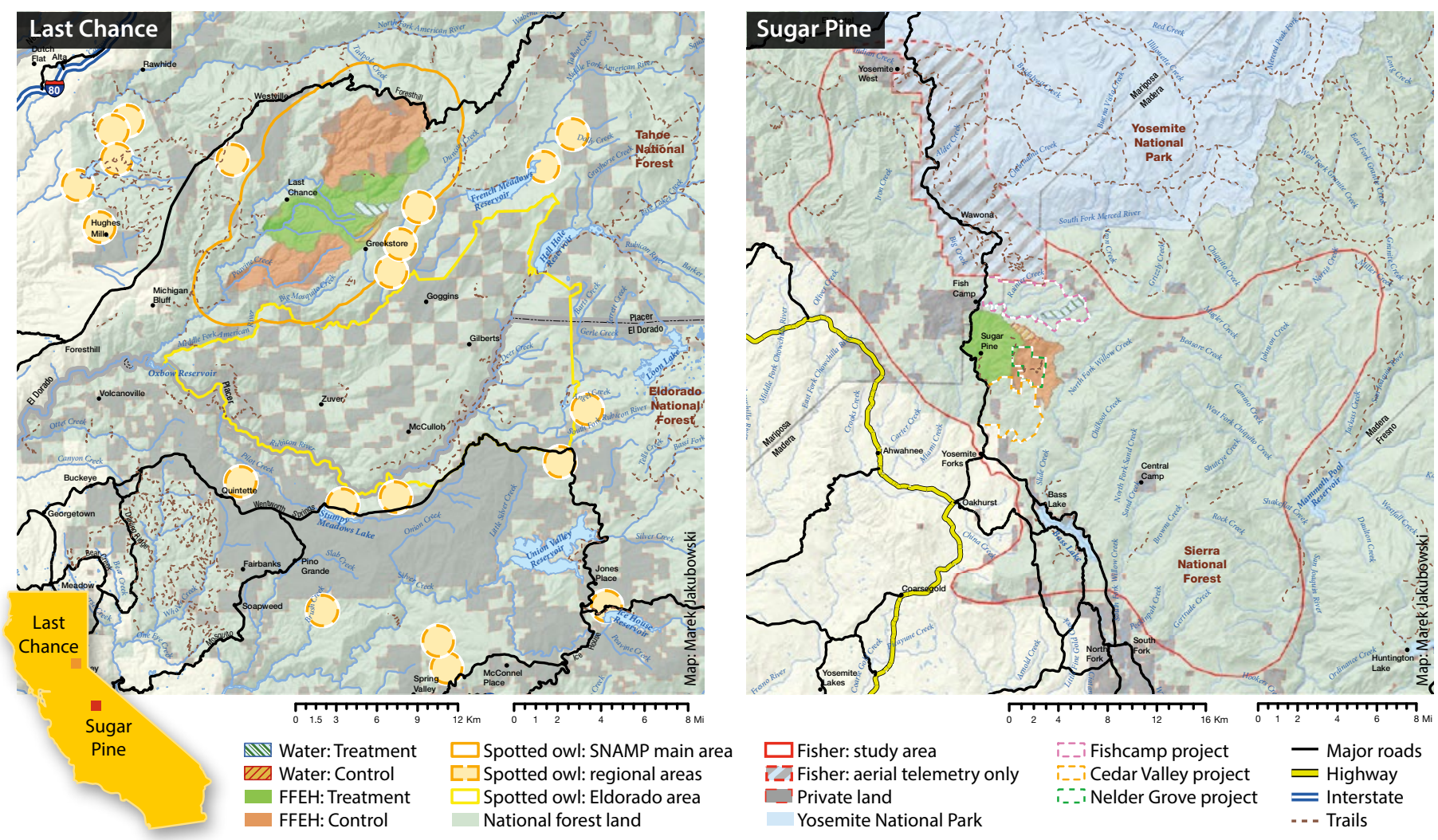

Fig. 2. SNAMP study areas. The northern site, Last Chance, is in the Tahoe National Forest; in this part of Placer County in the north-central Sierra Nevada, mixed-conifer forests include habitat for the California spotted owl. The southern site, Sugar Pine, is in the Sierra National Forest; on the western slope of the central Sierra Nevada, mostly in Madera County, this mixed-conifer forest provides habitat for the Pacific fisher and the California spotted owl.

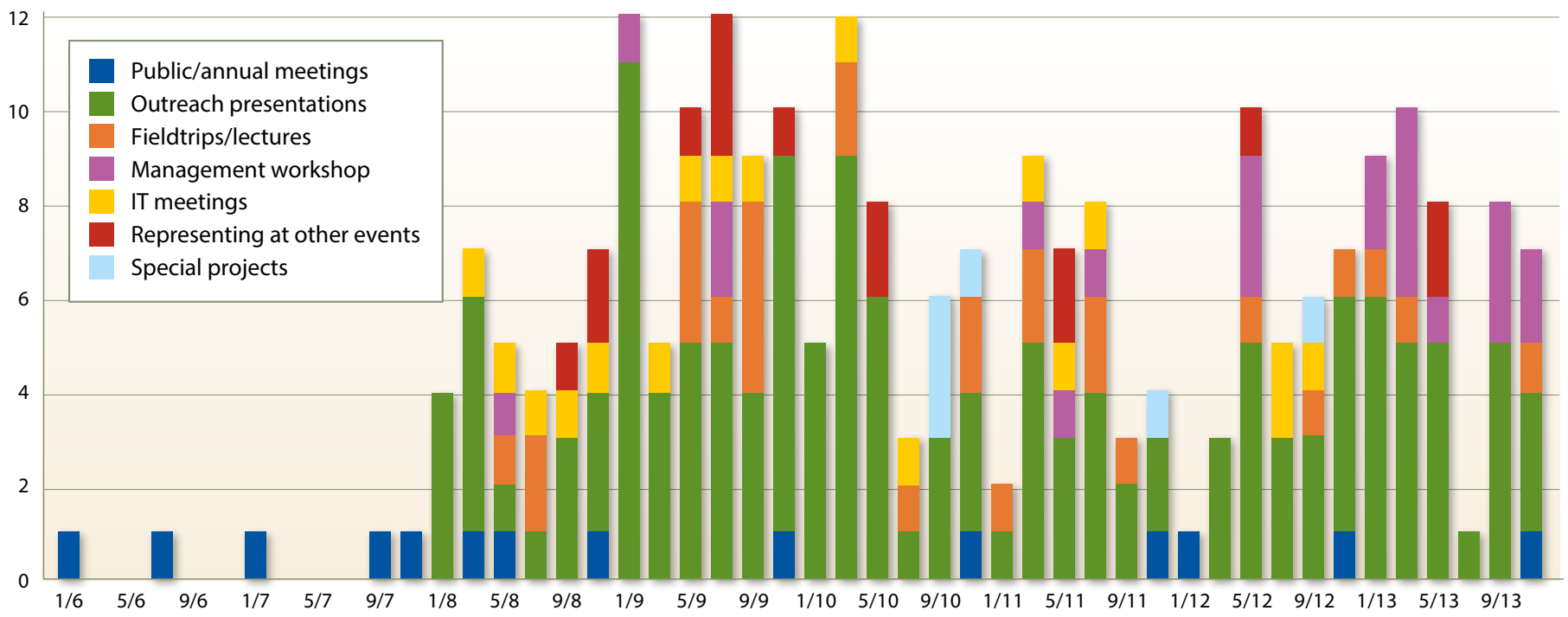

Fig. 3. UCCE facilitated 244 events from 2005 to 2013 to engage the public in SNAMP. 
has also frequently represented SNAMP at board of supervisors meetings, local interest group member meetings and other venues; a member of the public participation team lives near each of the two project sites, helping to make local connections and conduct outreach.

\section{Survey of stakeholders}

One of the project goals was to test and model outreach methods, and to assess the value of the adaptive management model to stakeholders. Just as it is important to understand how thinning treatments affected the forest, it is also important to determine what worked and building social legitimacy for decision making and establishing relationships that support learning and adaptation in the long run (Arnold et al. 2012).

Email contacts on a list maintained by UCCE to promote SNAMP events and update stakeholders were invited to respond to the web-based survey. The contact list was comprised of individuals who wanted to be informed about SNAMP progress or who had attended SNAMP events. Of the 647 people on the list who were invited, after four prompts, 168 completed the survey, for a $26 \%$ response rate, which is similar to return rates for other email surveys (Sheehan 2001). Survey

\section{Around half [of survey respondents] agreed SNAMP was improving relationships and increasing trust.}

what did not work about the participatory adaptive management approach, to provide guidance for future projects. Such assessments are also a "best practice" for UCCE outreach programs to determine if outreach is reaching the target audience.

To find out who was participating in SNAMP, what their different perspectives were, and what they believed they were getting out of the process, a survey was undertaken in summer 2010. The 2010 survey investigated aspects of SNAMP that the literature emphasizes as important to adaptive management projects: enhancing learning, creating shared understanding,

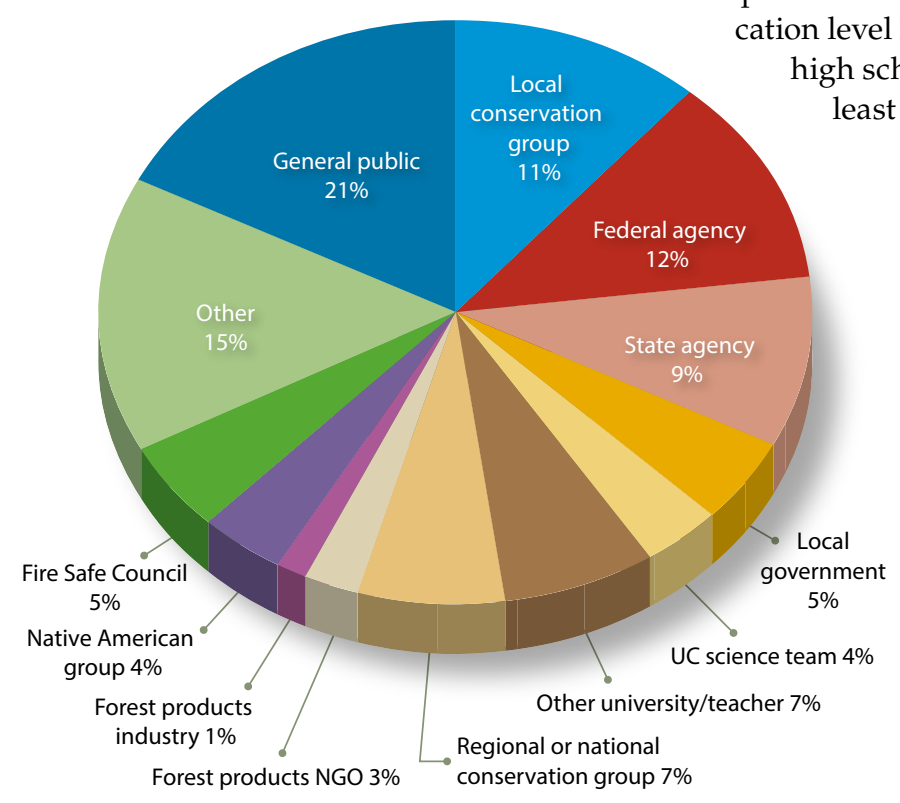

Fig. 4. Percentage of survey respondents who affiliated with predetermined groups in 2010. respondents are representative only of contacts interested enough to fill out the survey and inferential statistics are not applied. Survey questions were mostly multiple choice with the option for further comment; they were organized around the themes of who participates in SNAMP and how; what their perspectives are on forest health, adaptive management and the SNAMP process; and what they believe they are getting out of the project.

Of the participants who responded to the survey, $62 \%$ were male and $67 \%$ lived in a forested area. The average age was 52 , with the oldest 82 and the youngest 27 . All respondents who reported an eduon level had graduated from school and attended at east some college or trade school. A quarter had a bachelor's degree and $44 \%$ had completed a professional or graduate degree. A quarter of the respondents had not been to a SNAMP meeting but $80 \%$ of all respondents had visited the website or participated in a webinar. Of the respondents who had attended SNAMP events, most had been to four or fewer events $(68 \%)$.

There were a large number of respondents who described themselves as "members of the general public" (fig. 4). Many of the others were associated with federal or state agencies or conservation groups. Respondents also included members of forest products groups and Native American tribe representatives. Around half of respondents were from the counties around the study sites. The other half came from cities and rural areas all across the state (fig. 5), a benefit of the extended reach of the website (Kelly et al. 2012).

\section{What respondents said}

The vast majority of respondents felt that participation in SNAMP was worth their time and meetings were well organized and facilitated (fig. 6). There was strong agreement that SNAMP facilitated learning and that discussions between participants and presenters were encouraged and conducted in an open and informal manner with enough face-to-face contact with scientists and managers. Most agreed that they felt part of the project and that they were listened to by researchers. Around half agreed SNAMP was improving relationships and increasing trust. The sentiment that the SNAMP process was building consensus, though

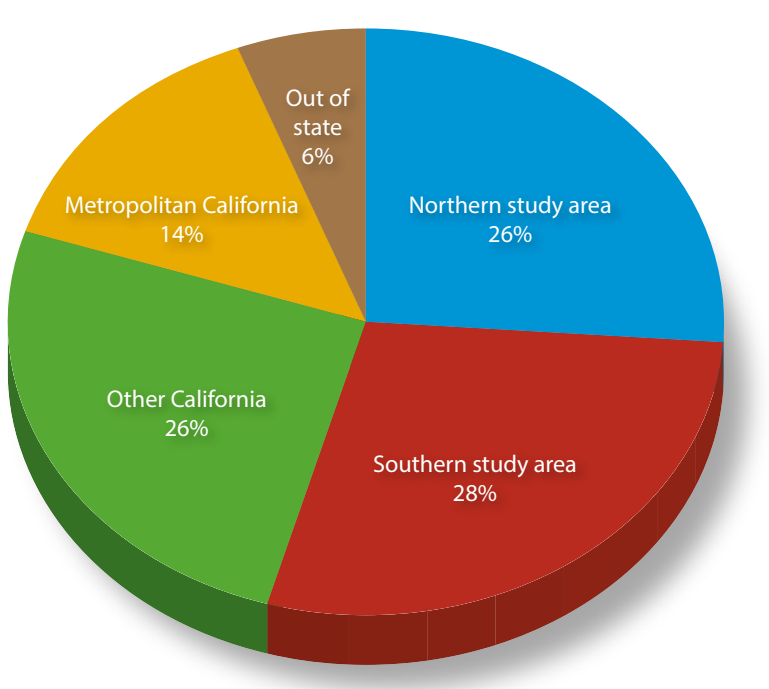

Fig. 5. Residence characteristics of 2010 survey respondents. 
not an explicit goal of the project, was shared by over one-third of respondents.

Shared understandings. The development of shared norms and understandings is argued to be key to successful teamwork among participants with divergent perspectives (Sulak and Huntsinger 2012). The goal is to deconstruct polarizing issues (Arnold et al. 2012) and create a hybrid culture with a common language (Sulak and Huntsinger 2012). To these ends, well-structured and -organized meetings that respect diverse sources of knowledge are important; they can create an environment conducive to developing such shared understandings (Arnold et al. 2012).

Workshops on collaborative adaptive management were held to help SNAMP participants learn communication strategies for productive meetings and to create a shared language to help build the long-term relationships to support learning and adaptation (Stringer et al. 2006). For example, the variety of definitions of adaptive management in Forest Service literature was discussed, and then compared to the science team's and stakeholders' definitions.

Multiple formats for sharing research plans and results and getting feedback were used in the SNAMP process, as has been shown beneficial in other studies (Arnold et al. 2012; Stringer et al. 2006) (fig. 3). UCCE continued to create new events and formats to address needs that came up as part of the iterative process (Stringer et al. 2006).

The survey indicates general satisfaction in this area of shared understandings, with strong agreement that the SNAMP process promoted learning and that the meetings were well organized (fig. 6).

Perspectives on forest health. To assess differences in stakeholder perspectives on subjects where learning and shared understandings would be important to perceptions of success at the end of the project, a series of questions was focused on forest health. The survey asked what indicates a healthy forest. More than $80 \%$ of respondents agreed that forest resilience, ecological processes and diversity, and regular, natural fires were indicators of forest health (fig. 7). More than half agreed that a healthy forest should sustainably produce timber and have well-spaced trees without debris buildup.
I have learned new things at SNAMP meetings

I have had adequate opportunity for face-to-face contact with UC scientists and/or Forest Service representatives

UC takes public participation seriously

SNAMP meetings are well organized and facilitated

My participation in SNAMP is worth my time

Meetings have encouraged discussion of a wide range of opinions from participants There has been open and informal discussion between the public, scientists and agencies

I am able to prepare for meetings using easily accessible information such as SNAMP agendas I have had enough opportunities to provide input to UC research

I am part of the project

UC has maintained its neutrality as well as is possible

Participants are listened to by UC researchers

My relationships have improved with other participants, agency or university staff

SNAMP is increasing trust among agency, public and university participant

SNAMP meetings are usually planned based on previous group discussion and participant interests

SNAMP is building consensus about forest management in the Sierra

SNAMP meetings are missing important stakeholders

Agree

Disagree Don't know

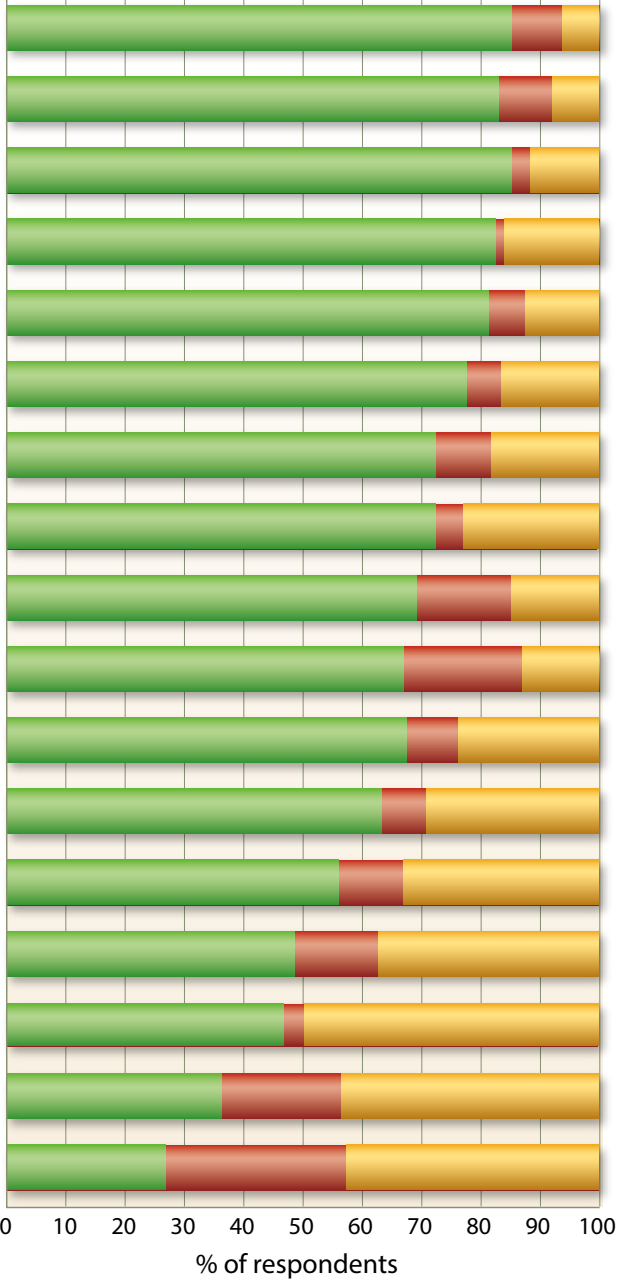

Fig. 6. Percentage of respondents to the 2010 survey who agreed that "Because of the way UC has facilitated participation for the SNAMP project so far, I think that ..."

All natural functions and processes are in place (T3)

It is able to be resilient (recover quickly) after fire or insect outbreak (T3)

There is a high diversity of plants and animals ( $\mathrm{T} 1$ )

It has regular, natural fires (T3)

It is fire resistant because the trees are well spaced and there is not a buildup of dead wood and shrubs (T2)

It provides a sustainable supply of timber (T4)

A Native American community can care for it in traditional ways (T4)

It looks like historical photographs of the same forest from the 19th century (T2)

The term forest health has political connotations and should not be used

People do not use the forest

Agree

Disagree

Don't know

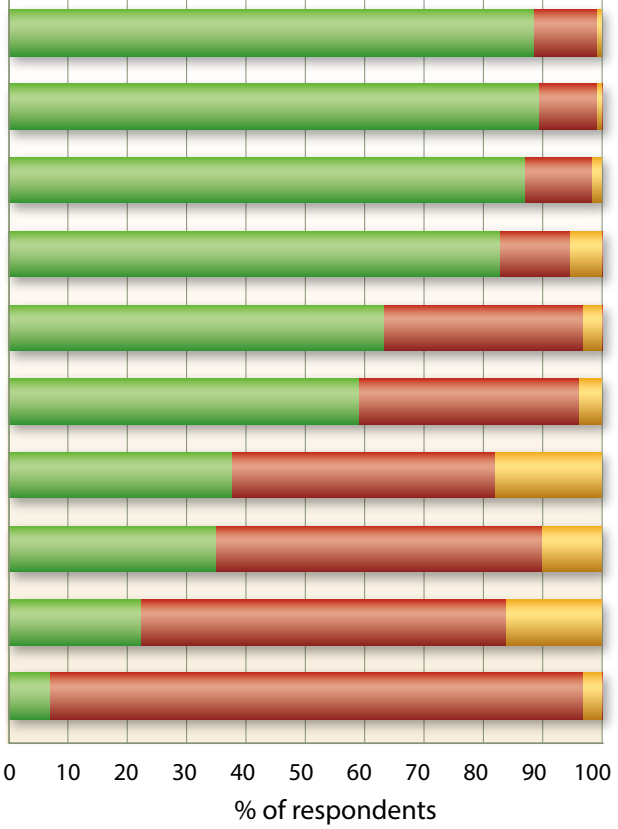

Fig. 7. Percentage of respondents to the 2010 survey who agreed that "A forest is healthy when ..." and the major themes: building biodiversity (T1), matching historical conditions (T2), promoting ecological processes (T3) and emphasizing active management (T4) (Sulak and Huntsinger 2012). 
Important to more than one-third was matching the look of a forest to its historical conditions; a similar number cared about Native American stewardship. Over a fifth of respondents agreed that the term forest health has political connotations. Less than $10 \%$ agreed that a forest is healthy when "people do not use it."

The response options were based on earlier interviews with a broad spectrum of participants conducted as part of the research approach (Sulak and Huntsinger 2012). The interview research conducted by the public participation team at the project outset found that definitions of forest health could be clustered around four general themes, though they do overlap: building biodiversity, matching historical conditions, promoting ecological processes, and emphasizing active management (Sulak and Huntsinger 2012). The email survey responses agreed most strongly with promoting ecological processes and building biodiversity, with fire and fire resistance as part of those processes (fig. 7). Active management, as reflected in maintaining a sustainable timber supply and Native American stewardship, and matching historical conditions, including spacing the trees, were also indicators of forest health for many respondents. Like the email survey respondents, very few interviewees stated a preference for a hands-off approach, and

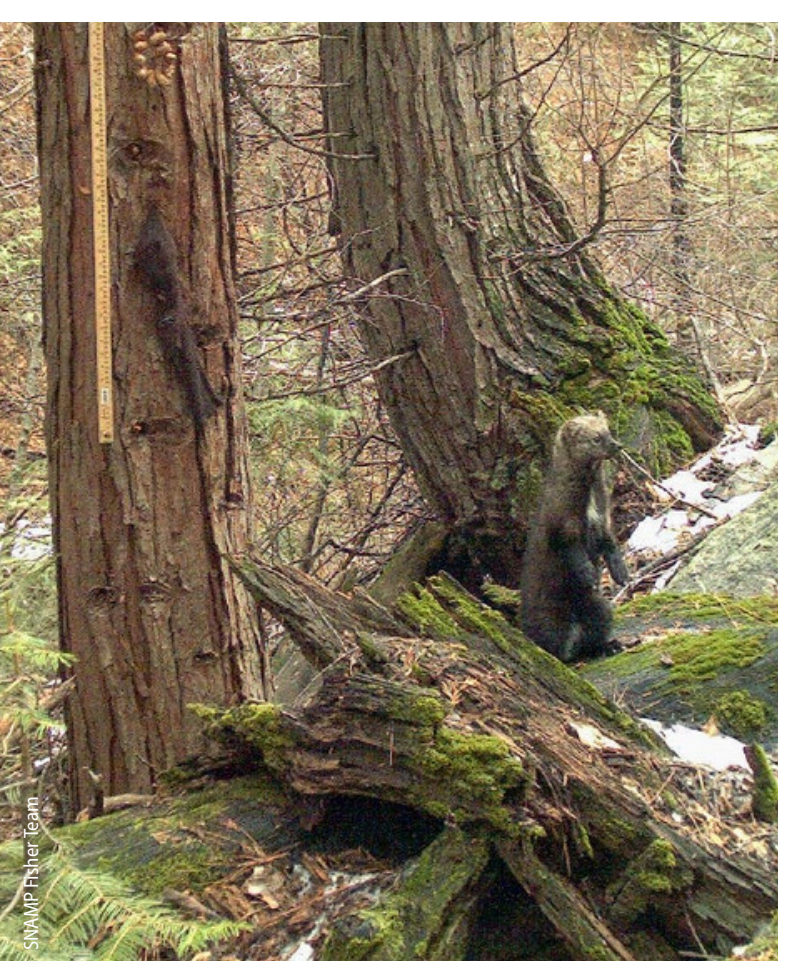

management was often mentioned as important to a healthy forest. Results from a follow-up survey at the end of the project will show whether notions of forest health changed during the SNAMP process.

Shared decision making. There are two major kinds of decision making within SNAMP, decisions about research made by the science team and decisions about management made by the Forest Service. Both groups have strong constraints on sharing decision making with stakeholders. These limitations are challenging to stakeholders but understanding them is key to SNAMP's success.

SNAMP fits into the category of top-down - rather than bottom-up, or grassroots - participatory adaptive management projects. A top-down project generally has a less organic set of relationships to begin with, making it harder to build and strengthen connections among participants, and a less democratic governance structure. Arnold et al. (2012) in their review of adaptive management processes point out that although under these conditions decision making is "often loosely equated to agreement by all parties, it more accurately reflects the perspective of stakeholders with the most power and a lack of active opposition by others."

The science team works with UCCE to seek public and agency feedback on research decisions. However, researchers hold that they must keep to the scientific practices set by their peers, which limits their ability to use all suggestions. At the behest of the public participation team, they agreed to make their decisions transparent and to provide a clear explanation when stakeholder input was not used. For example, in an online discussion board post, a public participant suggested study of a nearby severely burned area. A researcher explained that this could not fit the timeframe, budget and objectives of SNAMP or result in better management information, because there was no pre-fire data available from the site and the highseverity burn was not comparable with the prescribed fires used in SNAMP.

The science team held as a principle that public input leads to better research

In the Sugar Pine project area, SNAMP scientists studied the effects of thinning treatments on Pacific fisher (Martes pennanti) habitat quality and collected data on fisher survival and behavior within four watersheds. as well as management, but in actuality gave the public a consultative role rather than sharing decision making collaboratively. Stringer et al. (2006) state that power sharing can remain elusive in settings dominated by scientists and managers. To avoid some of the misunderstandings that have been a problem in other participatory management efforts (Wagner and Fernandez-Gimenez 2009), this limitation was made clear to all participants at the outset of the project. The survey indicates a positive relationship with the science team: The majority of respondents valued the learning opportunities, open discussions and face-to-face interactions with scientists and agreed that they showed interest in stakeholder input; respondents felt "part of the project" (fig. 6).

As for the Forest Service, it has been argued that full decision making authority cannot be devolved or abdicated outside of Congress's reach (Coggins 1999; Moote and McClaran 1997). This possible hurdle was raised at the beginning of the project in 2005, and again in April of 2008 by many participants in SNAMP workshops because of their aspiration to have true comanagement with the Forest Service, including shared decision making. Some participants were concerned that their contribution over the many years of SNAMP may ultimately be "a waste of time" if they cannot have more assurance that SNAMP results will be used by the Forest Service.

The perception that participants risk wasting resources and time has been expressed numerous times during participatory projects led by land management agencies. One comprehensive study of collaborative projects found that "collaboration experience was negatively associated with trust, indicating that participants with past experience in many collaborative groups were less trusting of other participants than participants with little previous collaborative experience" (Wagner and Fernandez-Gimenez 2009).

The Forest Service extends a fundamentally consultative role to SNAMP participants, with the expressed intention of adhering to the results of the project. The institutional limits to power sharing are challenging, but different aspects of an adaptive management program may have different levels of public involvement (Stringer et al. 2006); the diverse 
SNAMP formats allowed a collaborative approach when possible - for example, learning about and interpreting findings in integration meetings could be more collaborative than could forest management decisions. Field trips and group meetings provided for a free exchange of information that informed all participants, while providing feedback to scientists and managers.

Development of trust. In the third year of SNAMP, to develop trust and increase stakeholder input into the project, each research team began to hold annual integration meetings, where they shared and discussed their research progress with the public. The intention was to encourage detailed two-way conversations between researchers and the public, develop a committed core membership within SNAMP and collaboratively address the transition between scientific results and management action. There had previously been large public meetings quarterly, with a broader and more general agenda, but public feedback indicated preference for more intensive modes of interaction.

In 2010 , more than $80 \%$ of respondents felt that participation in SNAMP was worth their time. A large majority of those who did not "agree" that relationships were improving, consensus was being reached or trust was being developed responded that they simply "didn't know" yet, at the time of the survey (fig. 6). The closing survey at the end of UC's participation will provide more information about stakeholder response to the process once the analysis is finished.

Critical to stakeholders' long-term views of the project will be closing the adaptive management loop. An adaptive management cycle is considered complete when research results are used in future management decisions. This closure will largely take place after the UC role in SNAMP ends.

\section{Remaining questions}

Because of SNAMP, there is more clarity and understanding about forest management among different stakeholder groups, but how SNAMP information will be applied in the future, and whether stakeholders will continue as informed participants working with the Forest Service, is uncertain. It is known that the science team cannot co-conduct research, and the Forest Service cannot comanage the forest, and the public's role is constrained by the scientist's adherence to perceived scientific norms and the Forest Service's legal responsibility for decisions. Around these givens, however, there are indications of improved relationships and shared understandings; according to most of the survey respondents, SNAMP encouraged learning and opportunities for participation. The question is whether this learning and relationship formation will be enough to support Forest Service use of SNAMP results as it implements fuels reduction projects and to sustain continued learning and adaptation.
SNAMP participants remain concerned about whether the research results will be used in future management decisions. Public participation team researchers now hypothesize that the participation of a third party like UC in Forest Service adaptive management programs can help to reduce the concerns of stakeholders and increase the social legitimacy of decisions. More exploration is needed of UC's capacity as an independent research and outreach provider to mitigate a lack of trust and consensus, and an imbalance of power, between the public and land management agencies and among stakeholder groups. Also crucial is to explore what other opportunities for third-party participation there are in public land adaptive management projects. CA

\section{A. Sulak is Associate Specialist in the Center for} Forestry at UC Berkeley; L. Huntsinger is Professor in the Department of Environmental Science, Policy, and Management at UC Berkeley; and S.D. Kocher is UC Cooperative Extension Central Sierra Forestry/Natural Resources Advisor.

SNAMP is funded by USDA Forest Service Region 5, USDA Forest Service Pacific Southwest Research Station, UC Berkeley, UC Division of Agriculture and Natural Resources, U.S. Fish and Wildlife Service, California Department of Water Resources, California Department of Wildlife, California Department of Forestry and Fire Protection, Sierra Nevada Conservancy and the U.S. Agricultural Experiment Station. For more information about SNAMP, please see snamp.cnr.berkeley.edu or contact Susie Kocher at sdkocher@ucanr.edu.Thank you to Kim Rodrigues, Maggi Kelly, Ann Lombardo, Kim Ingram and the rest of the public participation team.

\section{References}

Arnold JS, Koro-Ljundberg M, Bartels W. 2012. Power and conflict in adaptive management: Analyzing the discourse of riparian management on public lands. Ecol Soc 17:19. http://dx.doi.org/10.5751/ES-04636-170119. Broussard SR, Whitaker BD. 2009. The Magna Charta of environmental legislation: A historical look at 30 years of NEPA-Forest Service litigation. Forest Policy Econ

$11: 134-40$.

Coggins GC. 1999. Regulating federal natural resources: A summary case against devolved collaboration. Ecol Law Quart 25:602

Finney MA. 2001. Design of regular landscape fuel treatment patterns for modifying fire growth and behavior. Forest Sci 47:219-28.

Gregory R, Ohlson D, Arvai JL. 2006. Deconstructing adaptive management: Criteria for applications to environmental management. Ecol Appl 16:2411-25.

Holling CS. 1978. Adaptive environmental assessment and management. New York: Wiley. 398 p.
Kelly M, Ferranto S, Lei S, et al. 2012. Expanding the table: The web as a tool for participatory adaptive management in California: A case study in the Sierra Nevada. J Environ Manage 109:1-11.

Moote MA, McClaran M. 1997. Viewpoint: Implications of participatory democracy for public land planning. J Range Manage 50:473-81.

Morghan KJR, Sheley RL, Svejcar TJ. 2006. Successful adaptive management-The integration of research and management. Rangeland Ecol Manag 59:216-9.

[NBC] NBC Nightly News, May 15, 2014. The Rising Costs of Fighting Fires in California. www.nbcnews.com/ nightly-news/rising-cost-fighting-fires-california-n106861 (accessed Feb. 10, 2015).

Sheehan KB. 2001. E-mail survey response rates: A review. J Comput-Mediat Comm 6. doi:10.1111/j.1083-6101.2001. tb00117.x.

Stringer LC, Dougill AJ, Fraser E, et al. 2006. Unpacking "participation" in the adaptive management of socialecological systems: A critical review. Ecol Soc 11:39.
[SNAMP] Sierra Nevada Adaptive Management Program. 2005. Memorandum of Understanding Regarding the Sierra Nevada Adaptive Management and Monitoring Plan. http://snamp.cnr.berkeley.edu/static/documents/ wp-uploads/MOU-SNAMP-Feb2005.pdf.

Sulak A, Huntsinger L. 2012. Perceptions of forest health among stakeholders in an adaptive management project in the Sierra Nevada of California. J Forest 110:312-7.

[UCST] University of California Science Team. 2007. University of California Science Team revised SNAMP workplan: January 16, 2007. http://snamp.cnr.berkeley. edu/documents/91/.

[USFS] United States Forest Service. 2004. Sierra Nevada Forest Plan Amendment — Final Supplemental Environmental Impact Statement Record of Decision. Report no. R5-MB-046. 72 p. www.fs.fed.us/r5/snfpa/final-seis/ index.html.

Walters CJ. 1986. Adaptive management of renewable resources. New York: MacMillan Press. 374 p.

Wagner CL, Fernandez-Gimenez, ME. 2009. Effects of community-based collaborative group characteristics on social capital. Environ Manage 44:632-45. 